\title{
ECHOCARDIOGRAPHY
}

A Journal of Cardiovascular Ultrasound and Alfied Techniques

\section{Feasibility, Symptoms, Adverse Effects and Complications Associated with Non-Invasive Assessment of Coronary Flow Velocity reserve in Women with Suspected or Known Coronary Artery Disease.}

\begin{tabular}{|r|l|}
\hline Journal: & Echocardiography \\
\hline Manuscript ID & ECHO-2017-0043.R2 \\
\hline Wiley - Manuscript type: & Original Investigation \\
\hline Date Submitted by the Author: & $\mathrm{n}$ a \\
\hline Complete List of Authors: & $\begin{array}{l}\text { Montisci, Roberta; University of Cagliari, Clinical Cardiology, AOU Cagliari } \\
\text { Ruscazio, Massimo; University of Cagliari, Clinical Cardiology, AOU Cagliari } \\
\text { Marchetti, Maria Francesca; University of Cagliari, Clinical Cardiology, } \\
\text { AOU Cagliari } \\
\text { Tuveri, Francesca; University of Cagliari, Clinical Cardiology, AOU Cagliari } \\
\text { Cacace, Cristina; University of Cagliari, Clinical Cardiology, AOU Cagliari } \\
\text { Congia, Michela; University of Cagliari, Clinical Cardiology, AOU Cagliari } \\
\text { Zedda, Norma; University of Cagliari, Clinical Cardiology, AOU Cagliari } \\
\text { Meloni, Luigi; University of Cagliari, Clinical Cardiology, AOU Cagliari }\end{array}$ \\
\hline Keywords: & $\begin{array}{l}\text { Coronary artery disease, Coronary circulation, Coronary flow reserve, } \\
\text { Stress echocardiography, Transthoracic echocardiography }\end{array}$ \\
\hline
\end{tabular}




\section{Feasibility, Symptoms, Adverse Effects and Complications Associated with Non-Invasive Assessment of Coronary Flow Velocity reserve in Women with Suspected or Known Coronary Artery Disease.}

\section{Running title: Assessment of Coronary Flow Velocity reserve in Women}

Roberta Montisci MD, Massimo Ruscazio MD, Maria Francesca Marchetti MD, Francesca Tuveri MD, Cristina Cacace MD, Michela Congia MD, Norma Zedda MD, and Luigi Meloni MD

From Clinical Cardiology, San Giovanni di Dio Hospital, Department of Clinical Science M. Aresu, University of Cagliari, Italy

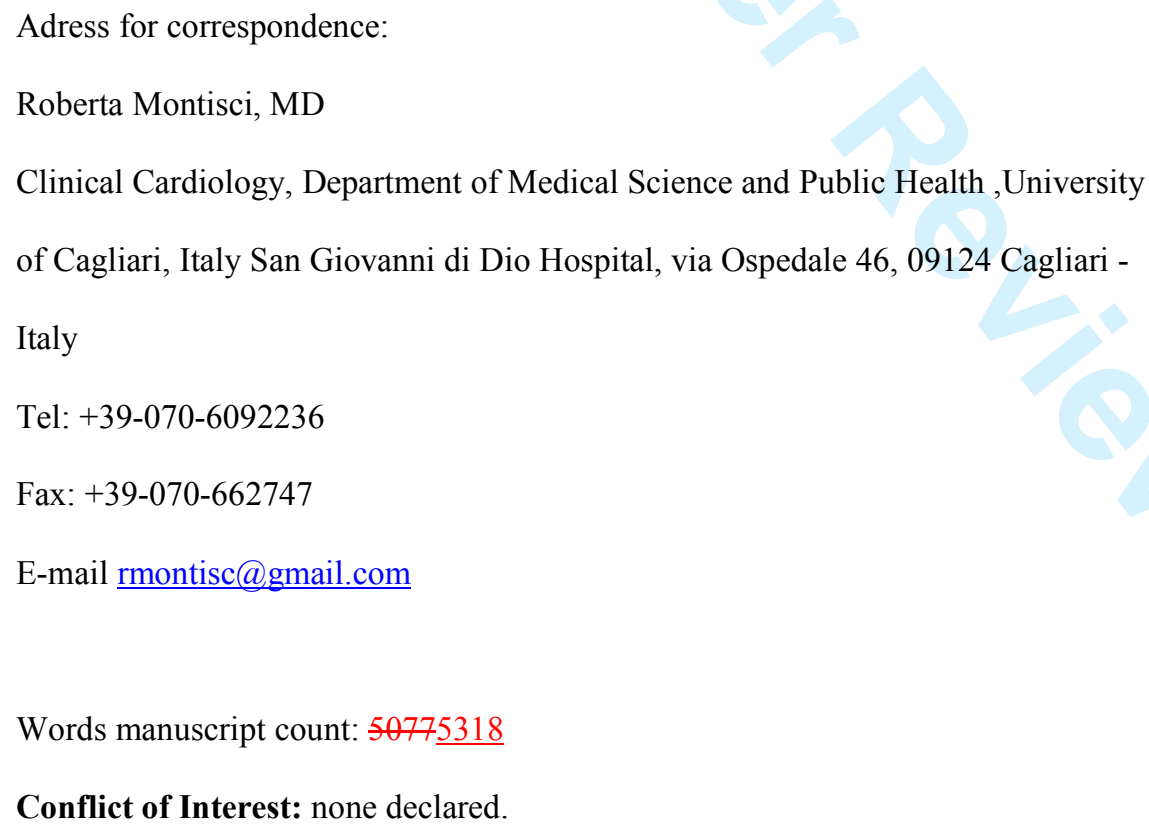




\begin{abstract}
Background. Microvascular coronary impairment, defined as reduced coronary flow reserve, represents the predominant etiologic mechanism of ischemia in women with chest pain and no obstructive coronary artery disease. Transthoracic echocardiography (TTE) is a non-invasive method for assessing coronary flow velocity reserve (CFVR) in the left anterior descending coronary artery (LAD). The purpose of this investigation was to define the safety profile, feasibility, adverse events and rate of complications of the test in women with suspected CAD. Methods. We evaluated CFVR in LAD with TTE during adenosine infusion in 1455 women aged: $66.4 \pm 11.9$ years.

Results. A complete CFVR study was achieved in 1429 pts (feasibility 98.2\%), the test being performed also in the early phase of acute coronary syndrome and on obese patients. Minor symptoms or adverse effects occurred in $43.7 \%$ of patients not requiring test termination: hyperpnea (16.7\%), flushing (9.4\%), atypical chest pain $(9.9 \%)$, headache (,6.6\%), minor arrhythmias (2.9\%), chest pain with EKG changes $(1.5 \%)$ were the symptoms reported. No major complications were observed.
\end{abstract}

Conclusions. Non-invasive assessment of CFVR in LAD by TTE is a very feasible method with very low incidence of adverse events and complications in women with suspected or known CAD. It is safe and can be used when evaluating female patients with atherosclerotic LAD disease or with coronary microvascular impairment. 
Key words: coronary flow reserve, coronary artery disease, transthoracic echocardiography, coronary microvascular dysfunction, adenosine

\section{INTRODUCTION}

Atherosclerosis and coronary artery disease (CAD) are the leading causes of morbidity and mortality in women in developed countries (1-3). It is also well known that in women non-obstructive CAD is more common than in men, and when obstructive $\mathrm{CAD}$ is present it usually involves a single vessel disease and a better preserved left ventricle function compared to men (4-5). Microvascular coronary impairment, defined as reduced coronary flow reserve (CFR), represents the predominant etiologic mechanism of ischemia in women with persistent chest pain and no obstructive coronary artery disease. Ischemia shown both through stress testing (6) and assessment of CFR is an important step for the evaluation of ischemic heart disease in women (7). Several methods are now available and have been established for measuring CFR. However, these methods are either invasive or costly and, consequently, rarely obtainable (8-9). Non-invasive assessment of coronary flow velocity reserve (CFVR) with transthoracic echocardiography (TTE) has been proposed in the past as a method for assessing CFR by measuring blood flow velocity before and after pharmacological-induced vasodilation (10), and is now being used more and more often as a method to evaluate the effects of epicardial coronary stenosis (10-12) and coronary microvasculature function (1317). Thus, the purpose of this study was to evaluate the safety and to analyze the feasibility, the adverse event profile and complication rate of non-invasive CFVR study assessed with TTE in women with known or suspected CAD over a period of 10 years in a single clinical cardiology center. 


\section{METHODS}

\section{Study group}

From January 2000 to December 2010 we performed 1455 CFVR studies in women referred to our stress echo laboratory for known and suspected CAD.

None of the patients had a history of asthma or advanced atrio-ventricular block or sick sinus syndrome not controlled by pacemaker. The patients (age $66.4 \pm 11.9$ years) were referred for CFVR studies for different reasons: planned follow up after elective and primary PTCA on LAD ( $n=933,64.1 \%)$, angina $(n=370,25.4 \%)$, hypertrophic cardiomyopathy $(n=11,0.8 \%)$, hypercholesterolemia $(n=38,2.6 \%)$, systemic sclerosis $(n=77,5.3 \%)$, others reasons $(n=25,1.7 \%)$ (table 1$)$.

All coronary active medications were not withdrawn before the echocardiographic study, although metilxantine-containing medications were withheld 48 hours before the study. Beverages containing metilxantine substances (coke, tea, coffee etc.) were prohibited for 24 hours before the study. Written informed consent to use medical records for scientific purposes was obtained from all patients. The study was approved by the Ethics Committee of our University Hospital.

\section{Study protocol}

Transthoracic echocardiography and color Doppler CFVR was evaluated using transthoracic Doppler before and after adenosine infusion. Echocardiography was performed with different echo machines (Acuson Sequoia ${ }^{\mathrm{TM}}$ ultrasound unit Siemens, IE33 Philips, My-Lab 30 gold Esaote) using a broad-band transducer with 

and then PW Doppler recording was obtained using color flow as a guide. Spectral trace of CFVR was characterized by a biphasic flow with a prevalent diastolic component (Fig 1). Contrast administration (Levovist ${ }^{\circledR}$, Schering AG, Berlin, Germany or Sonovue ${ }^{\circledR}$ Bracco) was performed, in our first series of patients $(142 / 1429,10 \%)$, both before and during adenosine intravenous administration in case of inadequate flow visualization at baseline. The ultrasound contrast agent was infused with a controlled -infusion pump (IVAC P4000 Anaesthesia Syringe pump) at a concentration of $300 \mathrm{mg} / \mathrm{ml}$ for Levovist ${ }^{\circledR}$ and at a concentration of 4.5 $\mathrm{mcg} / \mathrm{ml}$ for Sonovue with an infusion rate of $1 \mathrm{mg} / \mathrm{min}$ of a volume of 6-7 $\mathrm{ml}($ range of $0.5-2 \mathrm{ml} / \mathrm{min}$ ). Coronary flow velocity was measured in baseline conditions and during adenosine-induced coronary hyperemia. Adenosine was infused at a rate of $140 \mu \mathrm{g} / \mathrm{Kg} / \mathrm{min}$ in -5 minutes, or 7 minutes when myocardial perfusion scintigraphy was performed simultaneously. Adenosine infusions were stopped for the established protocol or for one of these reasons: early vasodilator response to adenosine; $85 \%$ of target heart rate; diagnostic ST segment change at EKG; sustained supraventricular or ventricular arrhythmias; symptomatic hypotension, high degree atrio-ventricular block.

Blood pressure and EKG were recorded at rest and every minute during adenosine infusion.

Coronary flow velocity reserve in the LAD was calculated as the ratio of peak diastolic velocity during hyperemia over peak diastolic velocity at rest (for each parameter the highest 3 were averaged) (10) (Figure 1) . 


\begin{abstract}
Statistics
Values were expressed as the mean $\pm \mathrm{SD}$ for continuous variables and as frequency and percentage for categorical variables. The Students' $t$ test was used for analysis of continuous data and the $\chi^{2}$ test or Fisher exact test for categorical variables . Relationships between adverse effects and age and reasons for the study were evaluated with the simple linear correlation coefficient $r$ (determination coefficient $\mathrm{r}^{2}$ ). All data were analyzed by using SPSS 20.0 statistical software (SPSS, Chicago, Il1).
\end{abstract}

\title{
RESULTS
}

\section{Feasibility and reasons for discontinuing adenosine infusion}

Of the consecutive 1455 patients referred to our laboratory, 1429 had a diagnostic non-invasive assessment of CFVR (feasibility 98.2\%) including those with acute coronary syndrome and with large body habitus; 1225 pts ( $85.7 \%)$ completed the protocol, 204 pts ( 14.2\%) achieving early maximal vasodilator effect and adenosine infusion was stopped before protocol scheduled time. Feasibility increased progressively after the first three years from $95,5 \%$ in 2000 to 99.3 in 2004 and then stabilized in the following years $(\mathrm{p}=0.004)$. In the remaining 26 patients (1.8\%) who did not complete the test, the study was interrupted because of hyperpnea $(8,0.5 \%)$, general malaise $(8,0.5 \%)$, failure to visualize LAD ( 2 , $0.13 \%)$, chest pain without EKG changes $(2,0.13 \%)$, nausea and headache (2, $0.13 \%)$, chest pain with ischemic EKG (1, 0.07\%), hypertensive status (systolic blood pressure $200 \mathrm{mmHg}, 1,0.07 \%)$, hypotension $(70 / 50 \mathrm{mmH}, 1,0.07 \%)$, and caffeine assumption $(1,0.07 \%)$.

\section{Duration of CFR test and hemodynamic parameters}


The mean duration of adenosine infusion was $3.45 \pm 2$ minutes (range 1-7 minutes). During adenosine infusion we observed a mild reduction in blood pressure and a moderate increase in heart rate. Systolic arterial pressure decreased from 139.9 \pm 21 to $134.7 \pm 21$ and diastolic arterial pressure from $81.3 \pm 10,6$ to $77.7 \pm 11,4$ ( $p<0.0001$ respectively), and only 3 patients had consistent reduction in systolic blood pressure (systolic blood pressure $<80 \mathrm{mmHg}$ ). Heart rate during adenosine increased progressively and significantly from $68.2 \pm 12.8$ to $86.3 \pm 16.3$ ( $<<0.0001$ ), with a range during adenosine infusion from 31 to 148 beats per minute.

\section{Results of coronary flow velocity reserve}

The average value of CFVR in the general population was $2.78 \pm 0.79 .189$ patients (13.2\%) had reduced CFVR $(\leq 2)$, and $1240(86,7 \%)$ had a normal CFVR $(>2.0)$. Of the patients with reduced CFVR, 125 had a history of known coronary artery disease with a previous PTCA on LAD and underwent a new coronary study: 120 patients (96\%) showed a restenosis on LAD and received a new PTCA. Fifty patients had a diagnosis of suspected angina and were scheduled for a coronary angiography: 42/50 (84\%) showed significant LAD coronary stenosis (lumen narrowing $>70 \%)$ and a PTCA was performed,whereas $8(16 \%)$ showed angiographically normal coronary artery and a diagnosis of microvascular angina was made.

Of the other 14 patients with reduced CFVR, 10 had a systemic sclerosis: 7 patients $(70 \%)$ performed a coronary computed tomography angiography with no evidence of coronary artery stenosis. Finally, four patients had a diagnosis of hypertrophic cardiomyopathy and a clinical follow-up program was scheduled. 


\begin{abstract}
Adverse effects of adenosine stress
No major complications were observed during all studies, such as death, myocardial infarction, sustained ventricular arrhythmia or high degree atrioventricular block or convulsive seizures.

The adverse effects of adenosine infusion were classified as non cardiac effects, cardiac and arrhythmias, as for other stress tests (18) (Figure 2). The total incidence of side effects of adenosine infusion was $43.7 \%$ : the incidence was similar over the years. We found an inverse correlation between age and experience of side effects $(\mathrm{r}=-0.13, \mathrm{p}<0.0001)$, especially flushing $(\mathrm{r}=0.16, \mathrm{p}<0.0001)$ and headache $(\mathrm{r}=0.11$, $\mathrm{p}=0.001$ ). None of the patients had adverse reactions to contrast administration.
\end{abstract}

\title{
Non-cardiac adverse effects
}

Minor symptoms or adverse non-cardiac effects occurred in 548 patients (38.3\%).

The most frequent symptom reported with regard to adenosine infusion was shortness of breath $(\mathrm{n}=239,16.7 \%)$. One-hundred and forty patients $(9.9 \%)$ suffered atypical chest pain without specific ST-T changes on the EKG .Other effects were flushing $(134,9.4 \%)$, headache $(95,6.6 \%)$, marked asthenia and general malaise $(80,5.5 \%)$ (Table 2$)$. The majority of non-cardiac side effects were well tolerated, and no patient required early suspension of the test before they could reach the maximum vasodilator effect in order to correctly assess the CFVR.

\section{Cardiac symptoms ad arrhythmias}

Cardiac symptoms occurred in 35 patients (2.4\%). Twenty-two patients (1.5\%) manifested typical angina pectoris with ischemic changes on the EKG, but the angina reversed spontaneously with adenosine infusion withdrawal. In only two 


\section{DISCUSSION}

This study demonstrates, for the first time, the high feasibility and tolerability of non-invasive assessment of CFVR with TTE in a large cohort of women with suspected or known coronary artery disease. Several methods are now available and well known for measuring CFR. However, these methods are either invasive or expensive and, consequently, rarely accessibile (8-9). Transesophageal Doppler echocardiography has been proposed in the past as a method for assessing CFVR 
by measuring blood flow velocity before and after pharmacological-induced vasodilation (10) and most recently cardiac magnetic resonance imaging with adenosine stress (25-27), although this test is still not available in most cardiology departments.

The accuracy and reproducibility of this method has been confirmed in a series of patients studies during cardiac catheterization with quantitative coronary angiography and intracoronary Doppler flow wire (12). In the clinical setting, CFVR is used for the diagnosis of coronary stenosis in the LAD and posterior descending coronary artery $(10-12,22)$ and to follow patients who have had a percoutaneus coronary angioplasty (23-24). Moreover, non-invasive CFVR is useful not only in the evaluation of coronaropatic patients, but also to assess different pathologies with functional and/or anatomic dysfunction of coronary microcirculation (13-17, 25-27) . Its role could be very important in the CAD evaluation in women. Sharaf et al., in the Women's Ischemia Syndrome Evaluation (WISE) study, reported that $30 \%$ of women with chest pain undergoing coronary angiography have normal or nonobstructive epicardial coronary arteries, $23 \%$ have a mild lesion and only $15 \%$ of patients have a multivessel disease (28). Obviously, the different pathophysiology strongly influences the accuracy of diagnostic tests commonly used in the study of ischemic heart disease. In fact, these tests are always focused on identifying critical stenosis of epicardial coronary vessels with difficult detection of those patients, mostly women, but at high risk for ischemic disease, who do not have hemodynamically significant coronary stenosis. The WISE group has proposed a flow chart which shows the role of evaluation of microvascular function (29), measuring the coronary flow reserve, especially since today it can be studied non-invasively with transthoracic echocardiography (10-17, 
22-27), and the recent European guidelines (30) for stable coronary artery disease recommend transthoracic Doppler echocardiography of the LAD to assess CFVR in patients with suspected microvascular angina (30).

\section{Clinieal usefulness of non-invasive assessment of CFVR in-women}

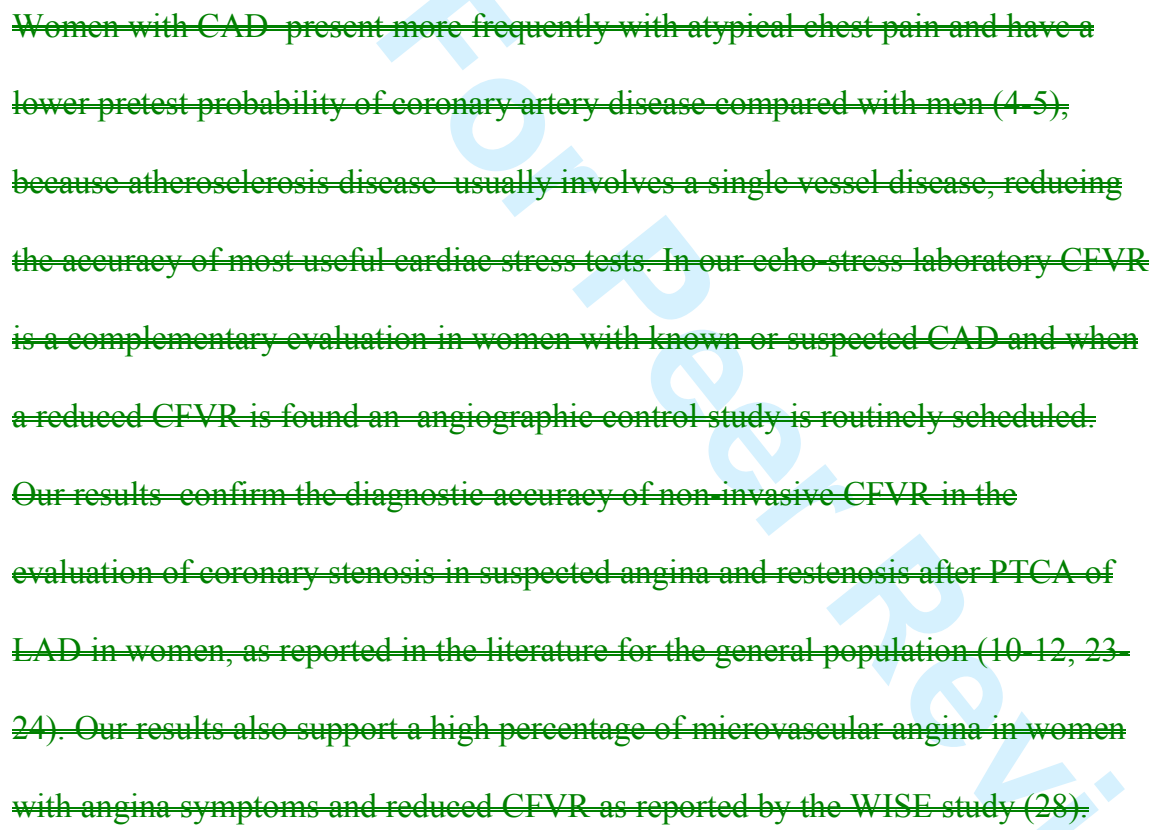

Clinical usefulness of non-invasive assessment of CFVR in women 
Women with CAD present more frequently with atypical chest pain and have a lower pretest probability of coronary artery disease compared with men (4-5), because atherosclerosis disease usually involves a single vessel disease, reducing the accuracy of most useful cardiac stress tests. In our echo-stress laboratory CFVR is a complementary evaluation in women with known or suspected CAD and when a reduced CFVR is found an angiographic control study is routinely scheduled. Our results confirm the diagnostic accuracy of non-invasive CFVR in the evaluation of coronary stenosis in suspected angina and restenosis after PTCA of $\underline{\underline{L A D} \text { in women, as reported in the literature for the general population }(10-12,23-}$ 24). Our results also support a high percentage of microvascular angina in women with angina symptoms and reduced CFVR as reported by the WISE study (28). Finally, CFVR studies show an important role in defining cardiac involvement and prognosis in patients with systemic sclerosis or severe psoriasis $(13,17,26,31-32)$ where coronary microcirculation is affected early on without clinical evidence of CAD. For these reasons we have organized in our Department a clinical protocol, shared with the Rheumatology department in order to assess CFVR in the routine cardiological evaluation of patients with systemic sclerosis, severe psoriasis or rheumatoid arthritis.

\section{Feasibility -and Adverse effects of- adenosine stress}

Our study examined for the first time a large series of women scheduled for noninvasive CFVR with intravenous adenosine infusion and evaluated not only feasibilty, as other studies did, (25), but also the safety and the adverse effects. Our 
study confirms the high feasibility $(98,8 \%)$ of a non invasive CFVR study in most of the patients, as well as in those with large body habitus or with an inadequate acoustic window, as previous small studies reported (10-12). The feasibility of the examination has grown steadily over the years, with the greater expertise of the operators, and has become extremely important from a clinical standpoint. In this regard, our data show that the test is very rapid. Indeed, the mean time of adenosine infusion was $3.45 \pm 2$ minutes and, due to adenosine rapid action (peak effect in $55 \pm 33$ s vs. $287 \pm 101$ with dipyridamole) (33), the hyperemic part of the study is very brief. Although we included patients at higher risk, such as women with angina pectoris or recent acute myocardial infarction, CFVR assessement with TTE test was well tolerated and was diagnostic in $98.2 \%$ of patients. Adenosine induces coronary arteriolar vasodilatation stimulating adenosine A2A receptors (34) on arteriolar vascular smooth muscle cells, causing vasorelaxation and increasing coronary flow, but adenosine non-selectively activates adenosine A1, A2B receptors, contributing to many of the common side effects and symptoms associated with adenosine infusion. To reduce the side effects of adenosine, a new selective (regadenoson) A2A receptor agonist has been proposed for the study of myocardial perfusion and coronary reserve and fractional flow reserve ( 35-37). Although literature data are promising, the side effects still persist, even with the regadenoson (38), and the costs are still high. In our study the incidence of total adverse effects could appear as high (43.7\%), but nevertheless much less than in previous studies involving adenosine (39), and none of these symptoms required the discontinuation of the infusion of adenosine before a diagnostic test. Ventricular and atrial premature beats were the most recurrent arrhythmias during adenosine infusion. In our large series of women, not one manifested life threatening 
arrhythmias or myocardial infarction or prolonged myocardial ischemia as reported in some cases in literature (40). The absence of induced ischemia or severe arrhythmia during adenosine stress in our patients could possibly be related to the fact that we did not discontinue the cardiac therapy (e.g. antianginal therapy) for the CFVR assessment, which is a well known limitation for other ischemia stress tests (41). Thus, our results show that non-invasive CFVR evaluation is as reliable and safe a test as other pharmacological stress tests, which utilise dobutamine or dypididamole $(18,42)$. In addition, concerning thedypiridamole and dobutamine stress tests, where it is often necessary to administer an antagonist (theophilline and beta blocker), in none of our patients was it necessary to infuse an antagonist of adenosine.

\section{CONCLUSION}

Non-invasive assessment of CFVR with TTE is a very feasible method with a very low incidence of adverse events and complications in women with suspected and known coronary artery disease. It can be used and safely performed in the evaluation of atherosclerotic LAD disease and microvascular impairment in women with suspected or known coronary artery disease.

\section{Acknowledgments}

The authors would like to thank Mrs Barbara Hildenbrand for her assistance in preparing the manuscript. 


\section{REFERENCES}

1. Centers for Disease Control and Prevention. State-Specific Mortality from Sudden Cardiac Death—United States, 1999. Available at: 
http://www.cdc.gov/mmwr/preview/mmwrhtml/mm5106a3.htm. Accessed August $25,2008$.

2. Writing Group Members, Mozaffarian D, Benjamin EJ, Go AS, Arnett DK, Blaha MJ, Cushman M, Das SR, de Ferranti S, Després JP, Fullerton HJ, Howard VJ, Huffman MD, Isasi CR, Jiménez MC, Judd SE, Kissela BM, Lichtman JH, Lisabeth LD, Liu S, Mackey RH, Magid DJ, McGuire DK, Mohler ER 3rd, Moy CS, Muntner P, Mussolino ME, Nasir K, Neumar RW, Nichol G, Palaniappan L, Pandey DK, Reeves MJ, Rodriguez CJ, Rosamond W, Sorlie PD, Stein J, Towfighi A, Turan TN, Virani SS, Woo D, Yeh RW, Turner MB; American Heart Association Statistics Committee; Stroke Statistics Subcommittee. Heart Disease and Stroke Statistics-2016 Update: A Report From the American Heart Association. Circulation. 2016 Jan 26;133(4):e38-360

3. Canto JG1, Kiefe CI2. Age-specific analyses of breast cancer versus heart disease mortality in women. Am J Cardiol. 2014 Jan 15;113(2):410-1

4. Bairey Merz CN, Shaw LJ, Reis SE. Ischemic heart disease in women: insights from the NHLBI-sponsored Women's Ischemia Syndrome Evaluation (WISE) Study. Part II: Gender differences in presentation, diagnosis, and outcome with regard to sex-based athophysiology of atherosclerosis, macro- and micro-vascular CAD. J Am Coll Cardiol 2006;47 Suppl:21s-9s

5. Mosca L, Banka CL, Benjamin EJ, Berra K, Bushnell C, Dolor RJ, Ganiats TG, Gomes AS, Gornik HL, Gracia C, Gulati M, Haan CK, Judelson DR, Keenan N, Kelepouris E, Michos ED, Newby LK, Oparil S, Ouyang P, Oz MC, Petitti D, Pinn VW, Redberg RF, Scott R, Sherif K, Smith SC Jr, Sopko G, Steinhorn RH, Stone NJ, Taubert KA, Todd BA, Urbina E, Wenger NK; Expert Panel/Writing Group.; American Academy of Physician Assistants.; American Association for Clinical Chemistry.; American Association of Cardiovascular and Pulmonary 
Rehabilitation.; American College of Chest Physicians.; American College of Emergency Physicians.; American Diabetes Association.; American Geriatrics Society.; American Society for Preventive Cardiology.; American Society of Echocardiography.; American Society of Nuclear Cardiology.; Association of Women's Health, Obstetric and Neonatal Nurses.; Global Alliance for Women's Health.; Mended Hearts, Inc.; National Black Nurses Association.; National Black Women's Health Imperative.; National Women's Health Resource Center.; North American Menopause Society.; Partnership for Gender-Specific Medicine at Columbia University.; Preventive Cardiovascular Nurses Association.; Society for Vascular Medicine and Biology.; Society for Women's Health Research.; Society of Geriatric Cardiology.; Women in Thoracic Surgery.; WomenHeart: the National Coalition for Women with Heart Disease.. Evidence-based guidelines for cardiovascular disease prevention in women: 2007 update. J Am Coll Cardiol 2007;49: $1230-50$.

6. Shaw LJ, Bugiardini R, Merz NB. Women and Ischemic Heart disease. JACC 2009;54:1561-75

7. Pepine CJ, David Anderson R, Sharaf BL, Reis SE, Smith KM, Handberg EM et al. Coronary Microvascular Reactivity to Adenosine Predicts Adverse Outcome in Women Evaluated for Suspected Ischemia. Results From the National Heart, Lung and Blood $\square$ Institute WISE (Women’s Ischemia Syndrome Evaluation) Study. J Am Coll Cardiol 2010;55:2825-32

8. Marcus ML, Wilson RF, White CW. Methods of measurement of myo- cardial blood flow in patients: a critical review. Circulation. 1987;76: 245-253

9. Graham SP, Cohen MD, Hodgson JM. Estimation of coronary flow reserve by intracoronary Doppler flow probes and digital angiography. Cathet Cardiovasc 
Diagn. 1990;19:214-221.

10. Caiati C, Montaldo C, Zedda N, Zedda N, Bina A, Iliceto S. New noninvasive method for coronary flow reserve assessment: contrast-enhanced transthoracic second harmonic echo Doppler. Circulation 1999;99:771-8.

11. Caiati C., Zedda N., Montaldo C., Montisci R., Iliceto S. Contrast- Enhanced Transthoracic Second Harmonic Echo Doppler With Adenosine. A Non Invasive, Rapid and Effective Method for Coronary Flow reserve Assessment. J Am Coll Cardiol.1999; 34 : 122-130

12. Caiati C, Montaldo C, Zedda N, Montisci R, Ruscazio M, Lai G, Cadeddu M, Meloni L, Iliceto S..Validation of a new noninvasive method (contrast enhanced transthoracic second harmonic echo Doppler) for the evaluation of coronary flow reserve: comparison with intracoronary Doppler flow wire. J Am Coll Cardiol 1999;34:1193-200

13. Montisci R, Vacca A, Garau P, Colonna P, Ruscazio M, Passiu G,Iliceto S, Mathieu A. Detection of early impairment of coronary flow reserve in patients with systemic sclerosis. Ann Rhe um Dis. 2003 Sep;62(9):890-3.

14. Tona F, Caforio AL, Montisci R, Gambino A, Angelini A, Ruscazio M, Toscano G, Feltrin G, Ramondo A, Gerosa G, Iliceto S. Coronary Flow Velocity Pattern and Coronary Flow Reserve by Contrast-Enhanced Transthoracic Echocardiography Predict Long-Term Outcome in Heart Transplantation. Circulation 2006 Suppl. 1:I49-I55

15. Tona F, Serra R, Di Ascenzo L, Osto E, Scarda A, Fabris R, Montisci R, Famoso G, Tellatin S, Foletto M, Giovagnoni A, Iliceto S, Vettor R. Systemic inflammation is related to coronary microvascular dysfunction in obese patients without obstructive coronary disease. Nutr Metab Cardiovasc Dis. 2014 Apr;24(4):447-53 
16. Osto E1, Fallo F, Pelizzo MR, Maddalozzo A, Sorgato N, Corbetti F, Montisci R,

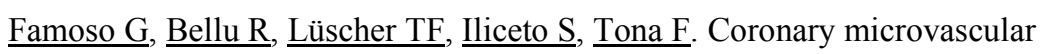
dysfunction induced by primary hyperparathyroidism is restored after parathyroidectomy. Circulation. 2012 Aug 28;126(9):1031-9.

17. Osto E, Piaserico S, Maddalozzo A, Forchetti G, Montisci R, Famoso G, Giovagnoni A, Peserico A, Iliceto S, Tona F. Impaired coronary flow reserve in young patients affected by severe psoriasis. Atherosclerosis. 2012 Mar;221(1):1137

18. Mertes H,Sawada SG,Ryan T, Segar DS,Kovacs R,Foltz J, et al. Symptoms, adverse effects,and complications associated with dobutamine stress echocardiography.experience in 1118 patients.Circulation.1993;88:15-19

19. Iliceto S, Marangelli V, Memmola C, Rizzon P. Transesophageal Doppler echocardiography evaluation of coronary blood flow velocity in baseline conditions and during dipyridamole-induced coronary vasodilation. Circulation. 1991;83:6169

20. Nagel E, Klein C, Paetsch I, Hettwer S, Schnackenburg B, Wegscheider K, Fleck E Magnetic Resonance Perfusion Measurements for the Noninvasive Detection of Coronary Artery Disease. Circulation. 2003;108:432-437

21. Shufelt CL1, Thomson LE, Goykhman P, Agarwal M, Mehta PK, Sedlak T, Li N, Gill E, Samuels B, Azabal B, Kar S, Kothawade K, Minissian M, Slomka P, Berman DS, Bairey Merz CN. CNB Cardiac magnetic resonance imaging myocardial perfusion reserve index assessment in women with microvascular coronary dysfunction and reference controls. Cardiovasc Diagn Ther 2013;3(3):153-160 
22. Voci P, Pizzuto F. Imaging of the posterior descending coronary artery. The last frontier in echocardiography. Ital Heart J 2001 Jun;2(6):418-22

23. Ruscazio M, Montisci R, Colonna P, Caiati C, Chen L, Lai G, Cadeddu M, Pirisi R, Iliceto S. Detection of coronary restenosis after coronary angioplasty by contrastenhanced transthoracic echocardiographic Doppler assessment of coronary flow velocity reserve. J Am Coll Cardiol 2002 Sep 4;40(5):896-903

24. Ruscazio M, Montisci R, Bezante G, Caiati C, Balbi M, Tona F, Lai G, Cadeddu M, Pirisi R, Brunelli C, Iliceto S, Meloni L. Early noninvasive evaluation of coronary flow reserve after angioplasty in the left anterior descending coronary artery identifies patients at high risk of restenosis at follow-up. J Am Soc Echocardiogr. 2012 Aug;25(8):902-10.

25. Cortigiani L, Rigo F, Gherardi S, Galderisi M, Bovenzi F, Picano ESicari R. Prognostic effect of coronary flow reserve in women versus men with chest pain syndrome and normal dipyridamole stress echocardiography. Am J Cardiol. 2010 Dec 15;106(12):1703-8

26. Montisci R, Ruscazio M, Lai S, Vacca A, Cauli A, Passiu G,Montisci M, Meloni L, Mathieu A, Iliceto S. Effect of a single IV administration of L-propionylcarnitine on myocardial microcirculation assessed by coronary flow velocity reserve measurement in patients with systemic sclerosis: a pilot study. Clin Ther. 2007 Jan;29(1):163-71

27. Tona F,Caforio ALP, Montisci R, Sarais C, Angelini A, Ruscazio M, Gambino A, Ramondo, Thiene G, Gerosa G, Iliceto S. Coronary Flow Reserve by ContrastEnhanced Echocardiography: a New Noninvasive Diagnostic Tool for Cardiac Allograft Vasculopathy. American Journal of transplantation 2006. 6 (5): 998-1003 
28. Sharaf BL1, Pepine CJ, Kerensky RA, Reis SE, Reichek N, Rogers WJ, Sopko G, Kelsey SF, Holubkov R, Olson M, Miele NJ, Williams DO, Merz CN; WISE Study Group. Detailed angiographic analysis of women with suspected ischemic chest pain (pilot phase data from the NHLBI-sponsored Women's Ischemia Syndrome Evaluation [WISE] Study Angiographic Core Laboratory). Am J Cardiol $2001 ; 87: 937-41$

29. Gulati M, Cooper-DeHoff RM, McClure C, Johnson BD, Shaw LJ, Handberg EM, Zineh I, Kelsey SF, Arnsdorf MF, Black HR, Pepine CJ, Merz CN. Adverse cardiovascular outcomes in women with nonobstructive coronary artery disease: a report from the Women's Ischemia Syndrome Evaluation Study and the St James Women Take Heart Project. Arch Intern Med 2009;169:843-50

30. Task Force Members, Montalescot G, Sechtem U, Achenbach S, Andreotti F, Arden C, Budaj A, Bugiardini R, Crea F, Cuisset T, Di Mario C, Ferreira JR, Gersh BJ, Gitt AK, Hulot JS, Marx N, Opie LH, Pfisterer M, Prescott E, Ruschitzka F, Sabaté M, Senior R, Taggart DP, van der Wall EE, Vrints CJ; ESC Committee for Practice Guidelines, Zamorano JL, Achenbach S, Baumgartner H, Bax JJ, Bueno H, Dean V, Deaton C, Erol C, Fagard R, Ferrari R, Hasdai D, Hoes AW, Kirchhof P, Knuuti J, Kolh P, Lancellotti P, Linhart A, Nihoyannopoulos P, Piepoli MF, Ponikowski P, Sirnes PA, Tamargo JL, Tendera M, Torbicki A, Wijns W, Windecker S; Document Reviewers, Knuuti J, Valgimigli M, Bueno H, Claeys MJ, Donner-Banzhoff N, Erol C, Frank H, Funck-Brentano C, Gaemperli O, GonzalezJuanatey JR, Hamilos M, Hasdai D, Husted S, James SK, Kervinen K, Kolh P, Kristensen SD, Lancellotti P, Maggioni AP, Piepoli MF, Pries AR, Romeo F, Rydén L, Simoons ML, Sirnes PA, Steg PG, Timmis A, Wijns W, Windecker S, Yildirir A, Zamorano JL. 2013 ESC guidelines on the management of stable 
coronary artery disease. The Task Force on the management of stable coronary artery disease of the European Society of Cardiology . European Heart Journal (2013) 34, 2949-3003

31. Vacca A, Montisci R, Garau P, Siotto P, Piga M, Cauli A, Ruscazio M, Meloni L, Formatted: Indent: Left: 0.05 Iliceto S, Mathieu A. Prognostic impact of coronary microcirculation abnormalities in systemic sclerosis: a prospective study to evaluate the role of non-invasive tests. Arthritis Res Ther. 2013 Jan 9;15(1):

32. Vacca A, Siotto P, Cauli A, Montisci R, Garau P, Ibba V, Mameli A, Passiu G, Iliceto S, Mathieu A. Absence of epicardial coronary stenosis in patients with systemic sclerosis with severe impairment of coronary flow reserve. Ann Rheum Dis. 2006 Feb;65(2):274-5.

31.33. Rossen JD, Quillen JE, Lopez AG, Stemberg RG,Talaman CL, Winniford MD. Comparison of coronary vasodilatation with intravenous dipyridamole and denosine.JACC.1991;18:495-91

32.34. Wilson RF, Wyche K, Christensens BV, Zimmer S, Laxson DD. Effects of adenosine on human coronary arterial circulation.Circulation 1990;82:1595-1606 33.35. Al Jaroudi W, Iskandrian AE. Regadenoson: A new myocardial stress agent. J Am Coll Cardiol 2009;54:1123-1130

34.36. Brinkert M1, Reyes E, Walker S, Latus K, Maenhout A, Mizumoto R, Nkomo C, Standbridge K, Wechalekar K, Underwood SR. et al. Regadenoson in Europe: First-year experience of regad- enoson stress combined with submaximal exercise in patients undergoing myocardial perfusion scintigraphy. Eur J Nucl Med Mol Imaging 2014;41:511-21 
35.37. Nair PK1, Marroquin OC, Mulukutla SR, Khandhar S, Gulati V, Schindler JT, Lee JS.. Clinical utility of regadenoson for assessing fractional flow reserve. JACC Cardiovasc Interv 2011;4:1085- 1092

36.38. Agarwal V, Depuey EG. Advanced heart block and unresponsive- ness after regadenoson administration during myocardial SPECT study. Int J Cardiol. 2014

37.39. Cerqueira MD, Verani MS, Schwaiger M, Heo J, Iskandrian AS. and Investigators of the Multicenter Adenoscan Trial. Safety profile of adenosine stress perfusion imaging: results from the Adenoscan Multicenter Trial Registry. J Am Coll Cardiol 1994;23:384-9.

38.40. Polad JE, Wilson LM. Myocardial infarction during adenosine stress test. Heart 2002;87(2):E2

39.41. Sicari R, Cortigiani L, Bigi R, Landi P, Raciti M, Picano E, on behalf of the Echo-Persantine International Cooperative (EPIC) Study Group and EchoDobutamine International Cooperative (EDIC) Study Group: The Prognostic value of pharmacological stress echo is affected by concomitant anti-ischemic therapy at the time of testing. Circulation 2004, 109:2428-31.

40.42. Ranhosky A, Kempthorne-Rawson J. The safety of intravenous dipiridamole thallium myocardial perfusion imaging. Circulation.1990;81:1205-1209 


\section{Figure Legends}

Figure 1 Tomographic plane orientation to left anterior descending coronary artery (LAD, top left) and color Doppler flow mapping in distal LAD in modified two chamber view in women with normal CFVR ( top right ) . Spectral Doppler tracing by sampling in distal LAD before (bottom left) and after adenosine infusion (bottom right). Coronary flow velocity reserve is calculated as adenosine diastolic peak velocity/basal diastolic peak velocity. LV= left ventricle; LA :left atrium; LAD: left descending artery

Figure 2 Tomographic plane orientation to left anterior descending coronary artery (LAD, top left) and color Doppler flow mapping in distal LAD in modified two chamber view in women with reduced CFVR ( top right ). Spectral Doppler tracing by sampling in distal LAD before (bottom left) and after adenosine infusion (bottom right). Coronary flow velocity reserve is calculated as adenosine diastolic peak velocity/basal diastolic peak velocity. LV= left ventricle; LA :left atrium; LAD: left descending artery

Figure 3 . Individual-value bar graphs showing percentage of non cardiac side effects (left), cardiac symptoms (middle) and arrhythmia B (right). 
Table 1. Age of the patients and the indications of CFVR study

\begin{tabular}{|l|c|c|}
\hline & N. patients & $\%$ \\
\hline Age (years) & $66.4 \pm 11.9$ & Range 14-89 \\
\hline Follow up post PTCA & 933 & 64.1 \\
\hline Suspected Angina pectoris & 370 & 25.4 \\
\hline Hypertrophic cardiomyopathy & 11 & 0.8 \\
\hline Hypercholesterolemia & 38 & 2.6 \\
\hline Systemic sclerosis & 77 & 5.3 \\
\hline Other reasons & 25 & 1.7 \\
\hline
\end{tabular}

Values were expressed as the mean $\pm \mathrm{SD}$ for continuous variables and as frequency and percentage for categorical variables; PTCA: percutaneus coronary angioplasty 
Table 2. side effects in 1429 patients

\begin{tabular}{|c|c|c|}
\hline & N.pz & $\%$ \\
\hline Non cardiac side effect: & 548 & 38.3 \\
\hline hyperpnea & 239 & 16.7 \\
\hline Headache & 95 & 6.6 \\
\hline Flushing & 134 & 9,4 \\
\hline Atypical chest pain & 140 & 9.9 \\
\hline Marked asthenia and general malaise & 80 & 5.5 \\
\hline Cardiac side effect: & 35 & 2.4 \\
\hline Typical angina & 22 & 1.5 \\
\hline Palpitations & 13 & 0.9 \\
\hline Symptomatic hypotension & 5 & 0.2 \\
\hline Arrhythmias: & 42 & 2.9 \\
\hline Sinus rhythm (no arrhythmias) & 1380 & 96.5 \\
\hline Supraventricular extrasystoles & 14 & 0.97 \\
\hline Ventricular extrasystoles & 17 & 1.2 \\
\hline Atrial fibrillation & 0 & 0 \\
\hline Ventricular Tachicardia & 0 & 0 \\
\hline Marked sinus bradycardia & 1 & 0.07 \\
\hline First degree atrioventricular block & 3 & 0,2 \\
\hline Second degree atrioventricular block & 7 & 0.5 \\
\hline 2:1 atrioventricular block & 6 & 0,4 \\
\hline Third degree atrioventricular block & 1 & 0.07 \\
\hline
\end{tabular}

Values were expressed as frequency and percentage for categorical variables 
Figure 1 Tomographic plane orientation to left anterior descending coronary artery (LAD, top left) and color Doppler flow mapping in distal LAD in modified two chamber view in women with normal CFVR (top right ). Spectral Doppler tracing by sampling in distal LAD before (bottom left) and after adenosine infusion (bottom right). Coronary flow velocity reserve is calculated as adenosine diastolic peak velocity/basal diastolic peak velocity. LV= left ventricle; LA :left atrium; LAD: left descending artery

$190 \times 142 \mathrm{~mm}(300 \times 300$ DPI $)$ 


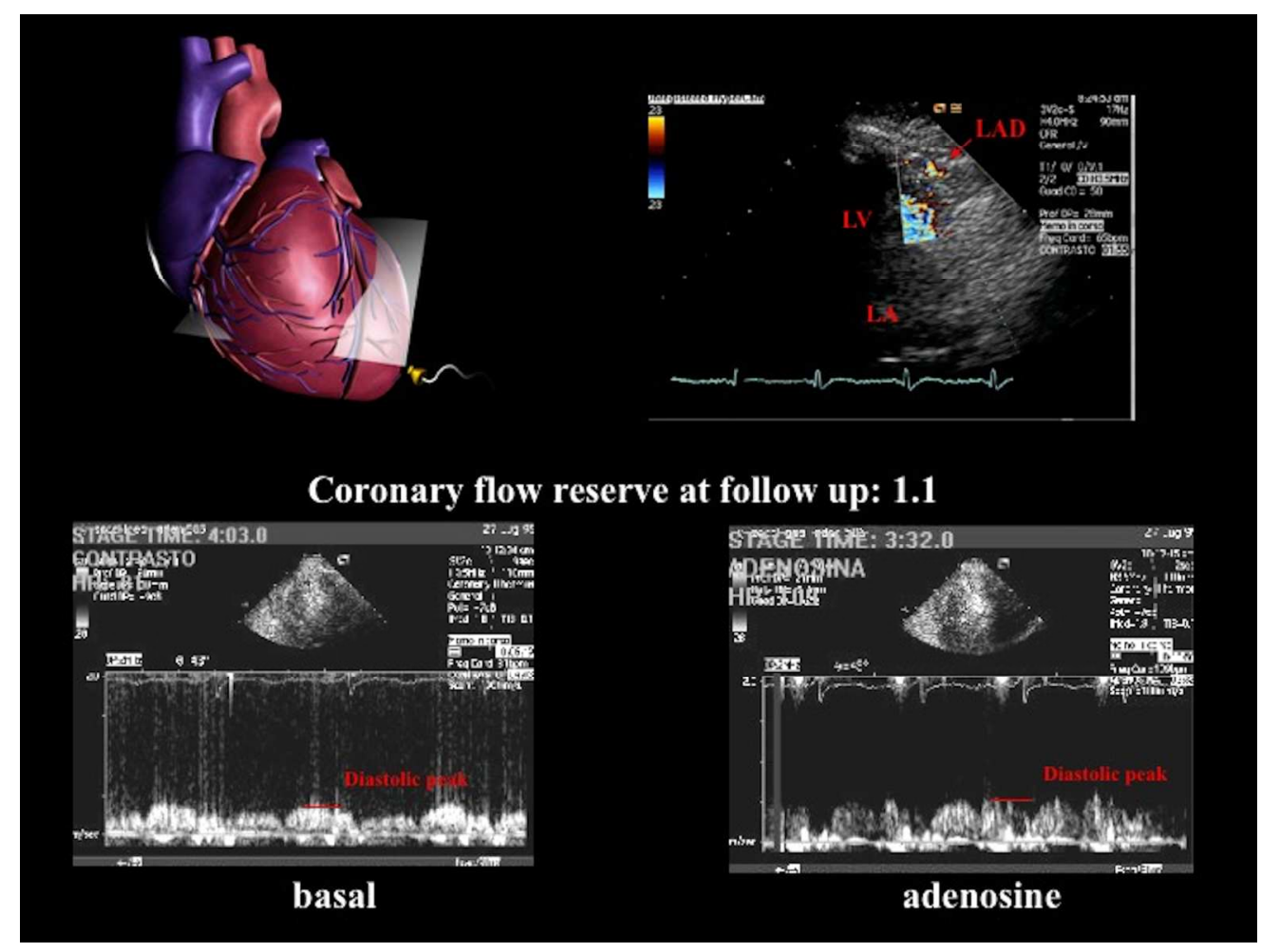

Figure 2 Tomographic plane orientation to left anterior descending coronary artery (LAD, top left) and color Doppler flow mapping in distal LAD in modified two chamber view in in women with reduced CFVR ( top right

). Spectral Doppler tracing by sampling in distal LAD before (bottom left) and after adenosine infusion (bottom right). Coronary flow velocity reserve is calculated as adenosine diastolic peak velocity/basal diastolic peak velocity. LV= left ventricle; LA :left atrium; LAD: left descending artery 
Figure 3 . Individual-value bar graphs showing percentage of non cardiac side effects (left), cardiac symptoms (middle) and arrhythmia B (right).

$190 \times 142 \mathrm{~mm}(300 \times 300 \mathrm{DPI})$ 
Reply to the Editor

1. The English must be properly corrected before a final decision can be given and if this is not done in a satisfactory manner, the manuscript will be rejected As requested by the Editor we reviewed the manuscript for syntax and grammar

Reply to Reviewer \# 1

Thank you very much to the Reviewer \#1 for the kind comments on our paper

Reply to Reviewer \# 2

1- comments 2 and 3 should be touched on in discussion as well.

We agree with the Referee indication. To clarify this aspect, we added a new paragraph on discussion session "comments 2 and 3 should be touched on in discussion as well.

" pag 11, lines 5-23: “) Women with CAD present more frequently with atypical chest pain and have a lower pretest probability of coronary artery disease compared with men 36 